\title{
ESCIMO.spread - a spreadsheet-based point snow surface energy balance model to calculate hourly snow water equivalent and melt rates for historical and changing climate conditions
}

\author{
U. Strasser and T. Marke \\ Department of Geography, Karl-Franzens University of Graz (KFU), Heinrichstr. 36, 8010 Graz, Austria
}

Received: 22 April 2010 - Published in Geosci. Model Dev. Discuss.: 28 May 2010

Revised: 13 August 2010 - Accepted: 1 September 2010 - Published: 12 November 2010

\begin{abstract}
This paper describes the spreadsheet-based point energy balance model ESCIMO.spread which simulates the energy and mass balance as well as melt rates at the snow surface. The model makes use of hourly recordings of temperature, precipitation, wind speed, relative humidity, and incoming global and longwave radiation. The effect of potential climate change on the seasonal evolution of the snow cover can be estimated by modifying the time series of observed temperature and precipitation by means of adjustable parameters. Model output is graphically visualized in hourly and daily diagrams. The results compare well with weekly measured snow water equivalent (SWE). The model is easily portable and adjustable, and runs particularly fast: an hourly calculation of a one winter season is instantaneous on a standard computer. ESICMO.spread can be obtained from the authors on request.
\end{abstract}

\section{Introduction}

The spreadsheet version of the physically based point snow surface model ESCIMO (Energy balance Snow Cover Integrated MOdel) (Strasser et al., 2002) has been developed as an easy-to-use, portable, and scientific tool for the hourly simulation of the energy balance, the water equivalent and melt rates of a snow cover in a commonly available format. ESCIMO.spread includes a 1-D, one-layer process model which assumes the snow cover to be a single and homogeneous pack, and which solves the energy and

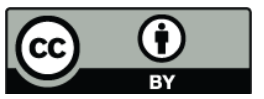

Correspondence to: U. Strasser (ulrich.strasser@uni-graz.at) mass balance equations for the snow surface by applying simple parameterizations of the relevant processes. Since the underlying physics is independent of space and time, the model represents an adequate tool to be applied for simulation of climate change effects. This is technically facilitated by implementation of climate change parameters for assumed temperature and precipitation trends. The spreadsheet version of the model presented and discussed in this paper includes one year of example meteorological recordings, the complete set of model formulae, both hourly and daily graphical output, and three quantitative measures of goodness of fit. This spreadsheet is freely available on request and can easily be adopted, modified and applied to other sites where the required input data is also available. In general, ESCIMO.spread is comparable with the spreadsheet-based glacier and snow melt study model published by Brock and Arnold (2000), which is also freely available. However, there are several distinctive differences between the two models: (i) ESCIMO.spread requires much less input data, i.e. hourly recordings of temperature, precipitation, wind speed, relative humidity, global as well as longwave radiation (albedo is parameterized), (ii) the file with test data and the model itself is in simple table format, does not invoke any Visual Basic macros, and can hence be applied by many spreadsheet programs on whatever platform they run (e.g., Microsoft Excel, Apple Numbers, OpenOffice Calc), (iii) the model is particularly fast and can easily be modified by simple change of the preset parameters and formulae in the spreadsheet, new results immediately being visualized, and, mostly, (iiii) ESCIMO.spread is capable of simulating the evolution of a seasonal snow cover under conditions of climate change by flexible adjustment of modified temperature and/or precipitation. Due to its 


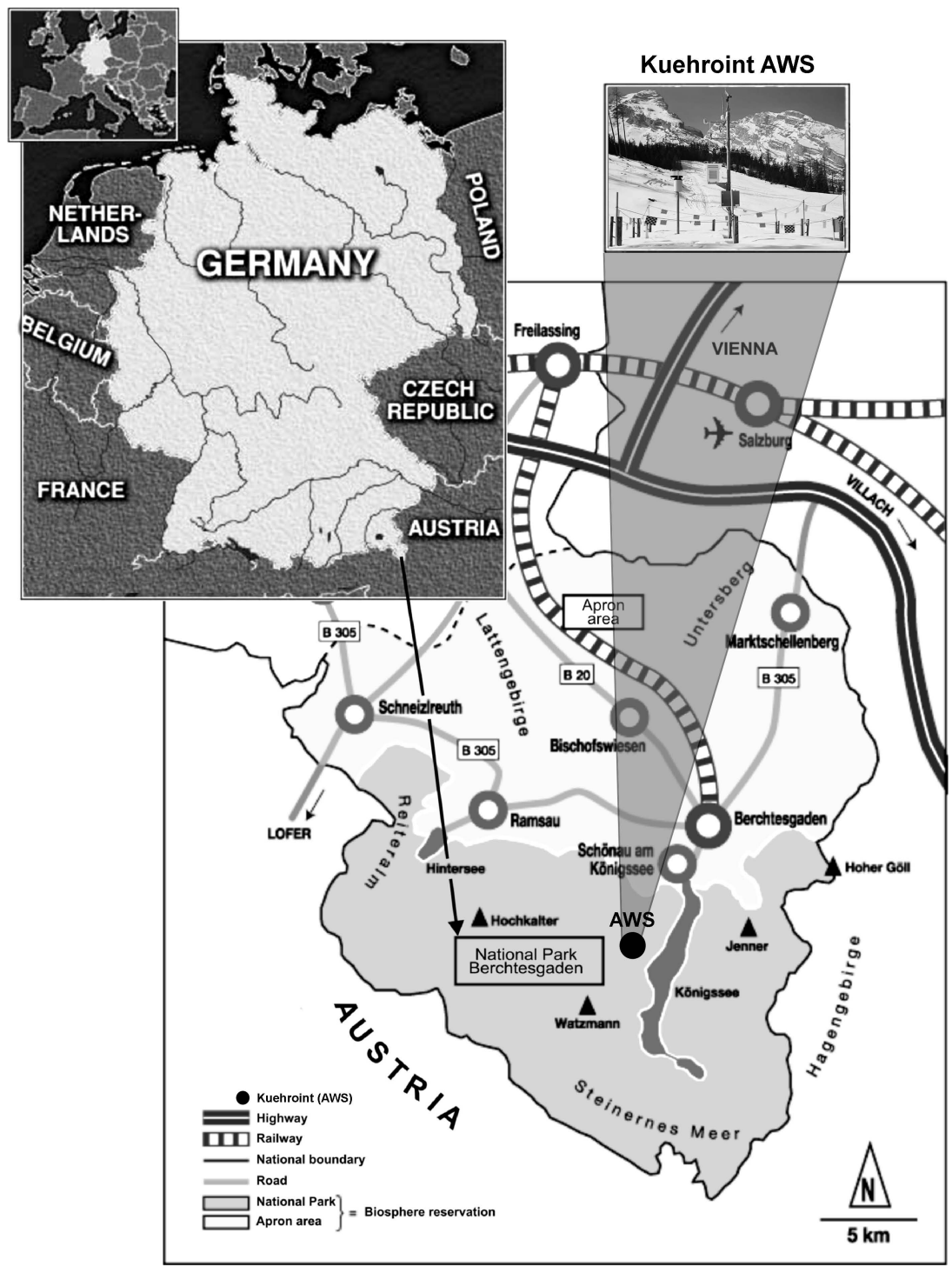

Fig. 1. The location of the Kuehroint site (1407 m a.s.1.) in Berchtesgaden National Park (Germany).

simplicity the model is specifically suitable for educational purposes (e.g., lab courses for students), and to be used with a laptop computer on site in the field. Here, the model can be utilized for a fast visualization of measured meteorological parameters, as well as simulated energy balance, snow water equivalent and snow melt. Thereby, the model can help to check the measurements for plausability and to explain differences between simulated and observed snow water equivalent e.g. due to wind induced transport of snow. However, compared to the Brock and Arnold (2000) model, this simplicity limits the detail in the process representation, particularly of the turbulent fluxes. ESCIMO.spread makes use of common bulk formulations for both the latent and sensible heat flux, and criteria like stability of the surface layer or roughness are not considered.
The demonstration test site which is chosen for the model application in this paper is the automatic weather station (AWS) at Kuehroint (1407 ma.s.l.) in the high Alpine area of the Berchtesgaden National Park (Bavarian Alps, Germany - Fig. 1). The station is part of the infrastructure maintained by the Bavarian Avalanche Warning Service (www.lawinenwarndienst-bayern.de) of the State Office for Environment. Kuehroint is situated at the foot of a gentle mountain slope (exposed to NE) at $47^{\circ} 34^{\prime} \mathrm{N}$ and $12^{\circ} 57^{\prime} \mathrm{E}$, respectively. There, a complete dataset of meteorological recordings is available for the winter season 2004/2005, comprising all required hourly meteorological observations. The data were captured every $10 \mathrm{~min}$ and then aggregated to the hourly values required for the application here. ESCIMO.spread can be obtained from the authors upon request. 
Table 1. Parameter values and constants used in ESCIMO.spread.

\begin{tabular}{llll}
\hline Parameter/constant & Symbol & Value & Unit \\
\hline Soil heat flux & $B$ & 2.0 & $\mathrm{~W} \mathrm{~m}^{-2}$ \\
Minimum albedo & $a_{\text {min }}$ & 0.45 & \\
Maximum albedo & $\left(a_{\text {min }}+a_{\text {add }}\right)$ & 0.90 & \\
Recession factor $(T \geq 273.16 \mathrm{~K})$ & $k$ & 0.12 & \\
Recession factor $(T<273.16 \mathrm{~K})$ & $k$ & 0.05 & \\
Hourly threshold snowfall for albedo reset & & $0.5 \times 10^{-3}$ & $\mathrm{~m}$ \\
Threshold temperature for precipitation phase detection & $T_{\mathrm{W}}$ & 275.16 & $\mathrm{~K}$ \\
Emissivity of snow & $\varepsilon$ & 0.99 & \\
Specific heat of snow $\left(\right.$ at $\left.0^{\circ} \mathrm{C}\right)$ & $c_{\mathrm{Ss}}$ & $2.10 \times 10^{3}$ & $\mathrm{~J} \mathrm{~kg}^{-1} \mathrm{~K}^{-1}$ \\
Specific heat of water $\left(\right.$ at $\left.5{ }^{\circ} \mathrm{C}\right)$ & $c_{\mathrm{Sw}}$ & $4.20 \times 10^{3}$ & $\mathrm{~J} \mathrm{~kg}^{-1} \mathrm{~K}^{-1}$ \\
Melting heat of ice & $c_{\mathrm{i}}$ & $3.337 \times 10^{5}$ & $\mathrm{~J} \mathrm{~kg}^{-1}$ \\
Sublimation/resublimation heat of snow $\left(\right.$ at $\left.-5^{\circ} \mathrm{C}\right)$ & $l_{\mathrm{S}}$ & $2.8355 \times 10^{6}$ & $\mathrm{~J} \mathrm{~kg}^{-1}$ \\
Stefan-Boltzmann constant & $\sigma$ & $5.67 \times 10^{-8}$ & $\mathrm{~W} \mathrm{~m}^{-2} \mathrm{~K}^{-4}$ \\
\hline
\end{tabular}

\section{Model theory}

In ESCIMO.spread, the energy balance of a snow surface is hourly modelled considering short- and longwave radiation, sensible and latent heat fluxes, energy conducted by solid or liquid precipitation as well as sublimation/resublimation and a constant soil heat flux. First, it is distinguished between melting condition (air temperature $\geq 273.16 \mathrm{~K}$ ) and no melt (air temperature $<273.16 \mathrm{~K}$ ). In the first case, a snow surface temperature of $273.16 \mathrm{~K}$ is assumed and melt can occur, the amount being determined by means of the energy balance remainder. If air temperature $<273.16 \mathrm{~K}$, snow surface temperature is assumed to equal air temperature, and no melt occurs. Snow accumulation is calculated for each timestep by (i) increasing the amount of SWE on the land surface by the amount of solid precipitation for a until now not snow covered surface or (ii) adding the amount of solid or liquid precipitation to the existing SWE at the land surface. Please note that no lateral processes are considered in these mass balance calculations.

The parameter values and constants used in ESCIMO.spread are listed in Table 1.

Generally, the energy balance for a snow pack can be expressed as:

$Q+H+E+M+A+B$

$=Q_{1 \downarrow}+Q_{1 \uparrow}+Q_{\mathrm{s} \downarrow}+Q_{\mathrm{s} \uparrow}+H+E+M+A+B=0$

where $Q$ is the shortwave and longwave radiation balance, $H$ the sensible heat flux, $E$ the latent heat flux, $M$ the energy potentially available for melt, $A$ the advective energy supplied by solid or liquid precipitation, and $B$ the soil heat flux for the current time step. The shortwave and longwave radiation balance is calculated by subtracting calculated outgoing short- $\left(Q_{\mathrm{s} \uparrow}\right)$ and longwave radiation $\left(Q_{1 \uparrow}\right)$ from measured incoming shortwave $\left(Q_{\mathrm{s} \downarrow}\right)$ and longwave radiation
$\left(Q_{1 \downarrow}\right)$. As soil heat flux measurements are scarcely available, a constant heat flux of $2 \mathrm{~W} \mathrm{~m}^{-2}$ is assumed for the model calculations within ESCIMO.spread.

All energy flux densities are expressed in $\mathrm{W} \mathrm{m}^{-2}$, energy flux densities directed to the surface are counted as positive, whereas energy flux densities directed from the surface are defined as negative.

The amount of shortwave radiation which is absorbed by the snow surface is determined by the albedo which depends on many factors (mainly grain size, density and impurity content) and varies with incidence angle and for different spectral bands. In ESCIMO.spread, snow albedo a is modelled using the ageing curve approach:

$a=a_{\min }+a_{\mathrm{add}} \cdot e^{-k n}$

where $a_{\text {min }}$ is the minimum albedo of (old) snow, $a_{\text {add }}$ is an additive albedo (with $a_{\text {min }}+a_{\text {add }}$ representing the maximum snow albedo), $n$ is the number of days since the last considerable snowfall (i.e. at least $0.5 \mathrm{~mm} \mathrm{~h}^{-1}$ ) and $k$ is a recession factor that is defined as -0.12 for positive temperatures and -0.05 for negative temperatures in the current model setup. Each time significant snowfall occurs the snow albedo is reset to its maximum value. This function integrates the change of the physical properties of the surface grain during its ageing.

Longwave emission of the snow cover $Q_{1 \uparrow}$ is calculated with snow emissivity $\varepsilon$ and the Stefan-Boltzmann-constant $\sigma$ :

$Q_{1 \uparrow}=\sigma \cdot \varepsilon \cdot T_{\mathrm{s}}^{4}$

where $T_{\mathrm{s}}$ is the snow surface temperature.

Since detailed measurements of the snow surface properties are usually not available at larger than the local scale, simple empirical descriptions of the turbulent fluxes are applied which are valid for medium roughness and a wide 
range of wind speeds. In areas where the contribution of the turbulent fluxes to the energy balance of the snowpack is small, the induced loss of accuracy is negligible. The parameterizations for the turbulent fluxes used here are valid for neutral or stable conditions. Following Kuchment and Gelfan (1996) the sensible heat flux $H$ is expressed with wind speed $W$ in $\mathrm{m} \mathrm{s}^{-1}$ as

$H=18.85 \cdot(0.18+0.098 \cdot W) \cdot\left(T-T_{\mathrm{s}}\right)$

and, accordingly, the latent heat flux $E$ is calculated as

$E=32.82 \cdot(0.18+0.098 \cdot W) \cdot\left(e_{1}-e_{\mathrm{s}}\right)$

where $e_{1}$ is the water vapour partial pressure at measurement level and $e_{\mathrm{S}}$ the water vapour saturation pressure at the snow surface, with both water vapour pressures being calculated using the Magnus formula and expressed in hPa. The small mass changes $\delta e$ in $\mathrm{mm}$ generated by sublimation or resublimation are simulated with $t$ being the duration between two model time steps ( $3600 \mathrm{~s})$ :

$\delta e=\frac{E \cdot t}{l_{\mathrm{S}}}$

where $l_{\mathrm{s}}$ is the sublimation/resublimation heat of snow.

The advective energy $A$ supplied by precipitation $P$ depends on its phase. If not measured, an adjustable threshold temperature $\left(T_{\mathrm{W}}\right)$ is assumed for the precipitation phase detection (see Table 1). Then, the energy advected by $P$ in $\mathrm{mm}$ is calculated for rainfall on snow (without refreezing) with

$A=P \cdot c_{\mathrm{sw}} \cdot(T-273.16)$

where $c_{\mathrm{sw}}$ is the specific heat of water. For snowfall, the advective energy is computed with

$A=P \cdot c_{\mathrm{Ss}} \cdot\left(T-T_{\mathrm{S}}\right)$

where $c_{\mathrm{ss}}$ is the specific heat of snow.

For the case of melting condition (air temperature $\geq$ $273.16 \mathrm{~K}$ ), all fluxes are calculated with an assumed snow surface temperature of $273.16 \mathrm{~K}$. If energy remains available for melt, its amount in $\mathrm{mm}$ is calculated with

melt $=\frac{M \cdot t}{c_{\mathrm{i}}}$

where $c_{\mathrm{i}}$ is the melting heat of ice.

ESCIMO has already been implemented in various versions and applied for numerous geographical positions and climatic conditions. Geographical scales thereby ranged from particular sites up to regional catchments $\left(100000 \mathrm{~km}^{2}\right)$. Thereby, the derivatives of the model, implemented in various programming languages, have been integrated in
- the SVAT scheme PROMET (Processes of Radiation, $M$ ass and $E$ nergy $T$ ransfer) for distributed, physically based water balance simulations including sophisticated formulations of the matter and energy fluxes in the soil, plants and in the atmospheric boundary layer (Mauser and Bach, 2009; Strasser and Mauser, 2001; Mauser and Schädlich, 1998; Strasser, 1998; Taschner et al., 1998),

- the integrative decision support system DANUBIA (www.glowa-danube.de) developed to simulate the effects of global change on the water balance of the upper Danube river basin (Prasch et al., 2008b; Mauser et al., 2007; Mauser, 2003; Ludwig et al., 2003; Mauser and Ludwig, 2002),

- the hydrological model PREVAH (Gurtz et al., 2003), e.g. to compute snow melt rates in a comparative, distributed application for the Dischma catchment (Switzerland) (Zappa et al., 2003), and

- the Alpine snow cover model AMUNDSEN (Alpine

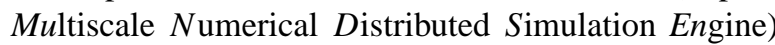
which is a physically based, distributed modelling system to simulate mountain-specific boundary layer meteorological processes, snow-canopy interaction, sliding snow, and the energy and mass balance of the ground snow cover (Strasser, 2008; Strasser et al., 2008). AMUNDSEN includes a stochastic weather generator to flexibly produce scenarios of future climate from historical observations (Strasser and Mauser, 2006).

\section{Model application}

ESCIMO.spread comprises the 5 interlinked data/model sheets illustrated in Fig. 2. The sheet Meteorological input includes the station recordings of temperature $(\mathrm{K})$, precipitation $(\mathrm{mm})$, wind speed $\left(\mathrm{m} \mathrm{s}^{-1}\right)$, relative humidity $(\%)$ as well as global and incoming longwave radiation $\left(\mathrm{W} \mathrm{m}^{-2}\right)$ in hourly resolution. For the application of the model at a specific site the user can easily copy and paste hourly time series of the required meteorological variables into this section of the spreadsheet.

The observed meteorological time series in the sheet Meteorological input are used in the sheet Model calculations for the calculation of the snow energy and mass balance processes following Eqs. (1)-(9). The sheet Model calculations is structured as follows. The first columns (columns A:E) contain the model time (year, month, day, hour and date) that is later used for the visualization of the model output. These columns are followed by the meteorological model input (columns F:K), i.e. the original recordings optionally modified by climate change parameters as described later in this section. The subsequent 6 columns (columns L:AB) comprise the formulae used for the model 


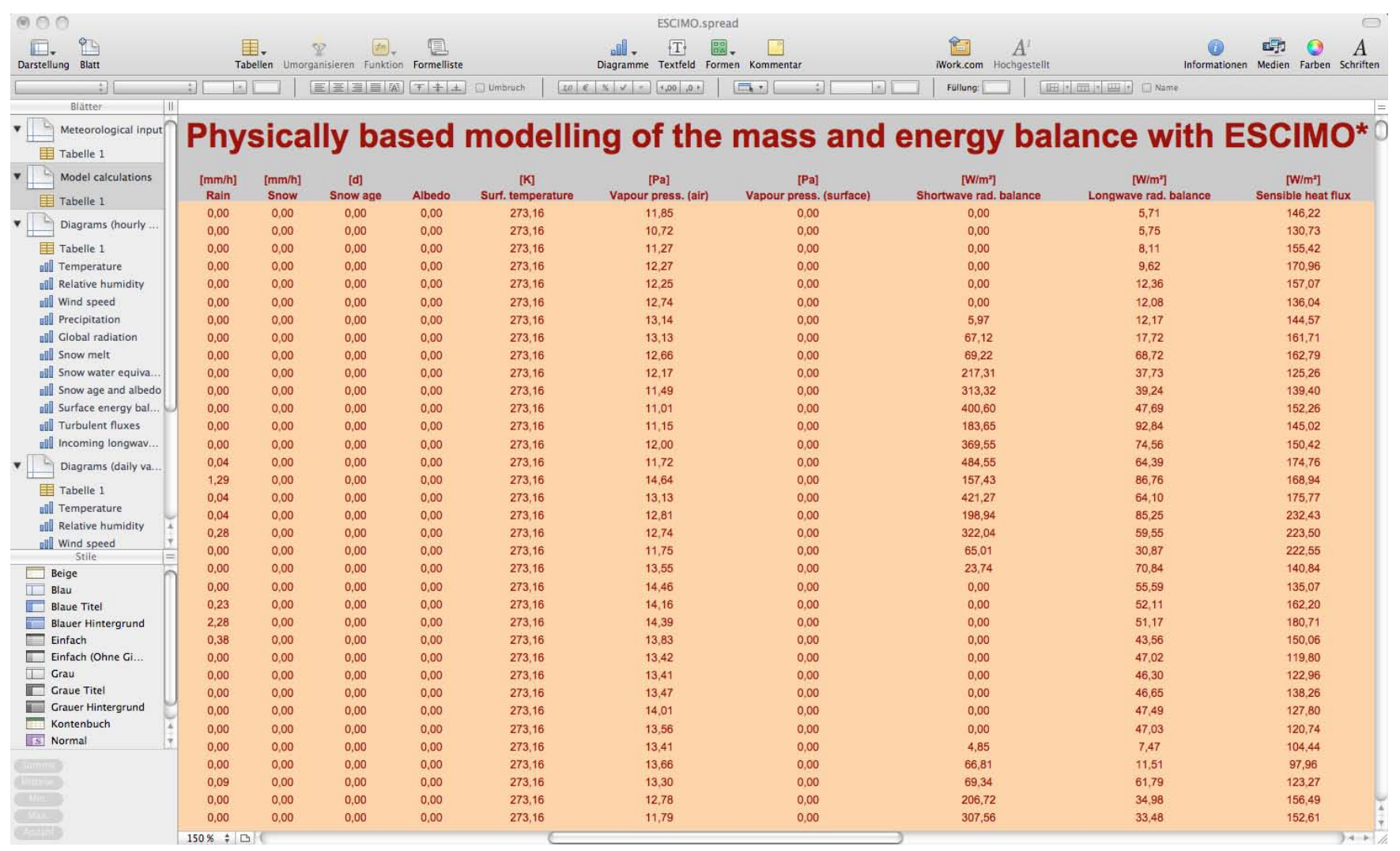

Fig. 2. Screenshot of the ESCIMO.spread spreadsheet in Apple Numbers.

calculations. The sequence of calculations is organized in such way, that the results of a given column (C) are used by the formula in subsequent columns (e.g., column $\mathrm{C}+1$ ). Similarly, the state variables calculated in a given row $(\mathrm{R})$ are providing the basis for the calculations in the subsequent row $(\mathrm{R}+1)$. The content of the first row of the calculations (row 4 in Fig. 2) differs in some columns from all following rows. This is the case when a state variable needs initialisation. All formulae in sheet Model calculations can easily be accessed and modified by clicking into an arbitrary cell of the table, modifying the formula, and then copying and pasting it in all lines of the respective column where the change should apply.

Adjacent to the model calculations, a column is reserved for the provision of snow water equivalent observations that can be used for the validiation of the model results (column $\mathrm{AC})$.

The model parameters required for the process descriptions (e.g., minimum albedo of snow or the snow emissivity) are defined in a separate area of the sheet Model calculations (cells AD4:AD27). These parameters may vary for different geographic regions and therefore require specific adjustment. The parameter values listed in the adjacent cells (AE4:AE17) represent physical constants and must therefore not be altered.
In order to apply the spreadsheet model for climate change impact analysis, parameters are provided to define potential changes in temperature and precipitation for the hydrological winter (November-April) and summer halfyear (May-October) separately (cells AD29:AD39). In case of temperature, the defined temperature increase is added to all hourly temperature recordings resulting in a mean temperature increase for the season considered. Precipitation changes are implemented by the definition of a relative increase or decrease of winter and/or summer precipitation that is, analogously to changes in temperature, used to modify the station recordings on a hourly time basis. This offers the option to increase or decrease total precipitation as well as to perform a shift of precipitation from one season to the other (summer to winter or vice versa). Since the defined climate change parameters are used in sheet Model calculations to create the respective modified time series of temperature and precipitation by modifying the original observations provided in Meteorological input, the user is supposed to only use the sheet Meteorological input to paste in meteorological observations, and not to overwrite the formulae in Model calculations.

The model output is illustrated in various diagrams with hourly and daily resolution in two seperate sheets. While sheet Diagrams (hourly values) directly represents the model 
calculations, the line plots in Diagrams (daily values) are generated on the basis of daily data (which are aggregates of the hourly model results); this second sheet scrolls much faster.

For the evaluation of the model results, and to demonstrate sensitivity of the models to changes in the parameter setup, the sheet Efficiency criteria has been implemented, performing the calculation of three different efficiency criteria (coefficient of determination, index of agreement, and Nash-Sutcliffe model efficiency; Krause et al., 2005). The values of these criteria are updated automatically by the spreadsheet engine. These are, however, only then meaningful if (i) the model is run for a period for which continuous hourly observed meteorology is available, and if (ii) a sufficient number of SWE recordings falls into the respective period (column AC in Model calculations). The spreadsheet which we promulgate includes simulations for the winter season 2004/2005 at Kuehroint in the Berchtesgaden Alps; the set of hourly meteorological station recordings is illustrated in Fig. 3. As the diagrams exhibit, erroneous recordings in the courses of temperature and wind speed exist during mid-february that result in extremely low values of calculated longwave radiation. These errors have not been corrected, on purpose, to stimulate a certain caution in the evaluation of model results, and to foster the development of a respective correction mechanism which can adequately be implemented in the spreadsheet itself. As these errors obviously result in a short-term understimation of the temperature conditions at the site considered in the present case and do not coincide with significant precipitation, their effect on simulated snow water equivalent is very little.

The results of the exemplary model run are shown in Fig. 4. For the winter 2004/2005 a continuous snow cover is simulated at the Kuehroint site from early November until late May with a peak in snow water equivalent of over $400 \mathrm{~mm}$ in the middle of March. Following the process formulations described in Eqs. (1)-(9) snow melt occurs if (i) a snow cover is present at the considered time step and (ii) the surface energy balance is positive indicating that there is energy available for snow melt. Taking a closer look at the diagrams exhibits that such conditions apply in the beginning of December as well as in the middle of March leading to notable melt. As Fig. 3 further exhibits, both these melting periods coincide with warm weather periods. The dependence of snow albedo on snow age as described with the ageing curve approach (Eq. 2) becomes clearly evident in Fig. 4: the snow surface albedo decreases with its age, and it is reset to its maximum value whenever a significant snowfall occurs. To evaluate the model performance for winter 2004/2005 the simulated snow water equivalent is compared to recordings which were taken weekly during the same period. The comparison reveals that the simulated snow water equivalent well matches with the samples taken in the field, although the model slightly underestimates the peak in observed snow water equivalent on 15 March 2005. It is however not quite clear, if these differences between the observations and the simulations are the result of model insufficiencies, or measurement errors.

\section{Model performance}

The ESCIMO spreadsheet model provides a simple method to validate the simulation by means of the three criteria (i) coefficient of determination, (ii) index of agreement, and (iii) Nash-Sutcliffe model efficiency. Thereby, the coefficient of determination $R^{2}$ from a linear regression of modeled versus observed SWE of $\mathrm{n}$ time steps is defined as the squared value of the coefficient of correlation and is given with:

$$
R^{2}=\left(\frac{\sum_{i=1}^{n}\left(\mathrm{SWE}_{\mathrm{obs}}{ }^{i}-\overline{\mathrm{SWE}}_{\mathrm{obs}}\right)\left(\mathrm{SWE}_{\mathrm{mod}}{ }^{i}-\overline{\mathrm{SWE}}_{\mathrm{mod}}\right)}{\sqrt{\sum_{i=1}^{n}\left(\mathrm{SWE}_{\mathrm{obs}}{ }^{i}-\overline{\mathrm{SWE}}_{\mathrm{obs}}\right)^{2}} \cdot \sqrt{\sum_{i=1}^{n}\left(\mathrm{SWE}_{\mathrm{mod}}{ }^{i}-\overline{\mathrm{SWE}}_{\mathrm{mod}}\right)^{2}}}\right)^{2}
$$

where $\mathrm{SWE}_{\mathrm{obs}}^{i}$ is the observed SWE at the $i$-th location, $\mathrm{SWE}_{\text {mod }}^{i}$ is the modeled SWE at corresponding location, $\overline{\mathrm{SWE}}_{\mathrm{obs}}$ is the mean observed SWE, and $n$ is the number of time steps which comprise the period of comparison.

The index of agreement IA represents the ratio of the mean square error and the potential error. It is calculated following (Willmot, 1984) as:

$$
\mathrm{IA}=1-\frac{\sum_{i=1}^{n}\left(\mathrm{SWE}_{\mathrm{obs}}{ }^{i}-\mathrm{SWE}_{\mathrm{mod}}^{i}\right)^{2}}{\sum_{i=1}^{n}\left(\left|\mathrm{SWE}_{\mathrm{mod}}{ }^{i}-\overline{\mathrm{SWE}}_{\mathrm{obs}}\right|+\left|\mathrm{SWE}_{\mathrm{obs}}{ }^{i}-\overline{\mathrm{SWE}}_{\mathrm{obs}}\right|\right)^{2}}
$$

Finally, Nash-Sutcliffe model efficiency (NSME), defined as one minus the sum of the absolute squared differences between the predicted and observed values, normalized by the variance of the observed values, is computed with (Nash and Sutcliffe, 1970):

$$
\mathrm{NSME}=1-\frac{\sum_{i=1}^{n}\left(\mathrm{SWE}_{\mathrm{obs}}{ }^{i}-\mathrm{SWE}_{\mathrm{mod}}^{i}\right)^{2}}{\sum_{i=1}^{n}\left(\mathrm{SWE}_{\mathrm{obs}}{ }^{i}-\overline{\mathrm{SWE}}_{\mathrm{obs}}\right)^{2}}
$$

The application of three different efficiency criteria allows two analyze their different sensitivity to changes in the meteorological input in the framework of student courses and stimulates the discussion of their individual significance. A big drawback of the coefficient of determination for example is, that this efficiency criterion does merely consider the covariance of simulations and observations, but not the differences between simulations and observations. As evident from Eqs. (11) and (12), the two criteria of the IA and the NSME do consider these deviations from the observations and therefore represent valuable supplementary efficiency criteria to be included in the model validation. 

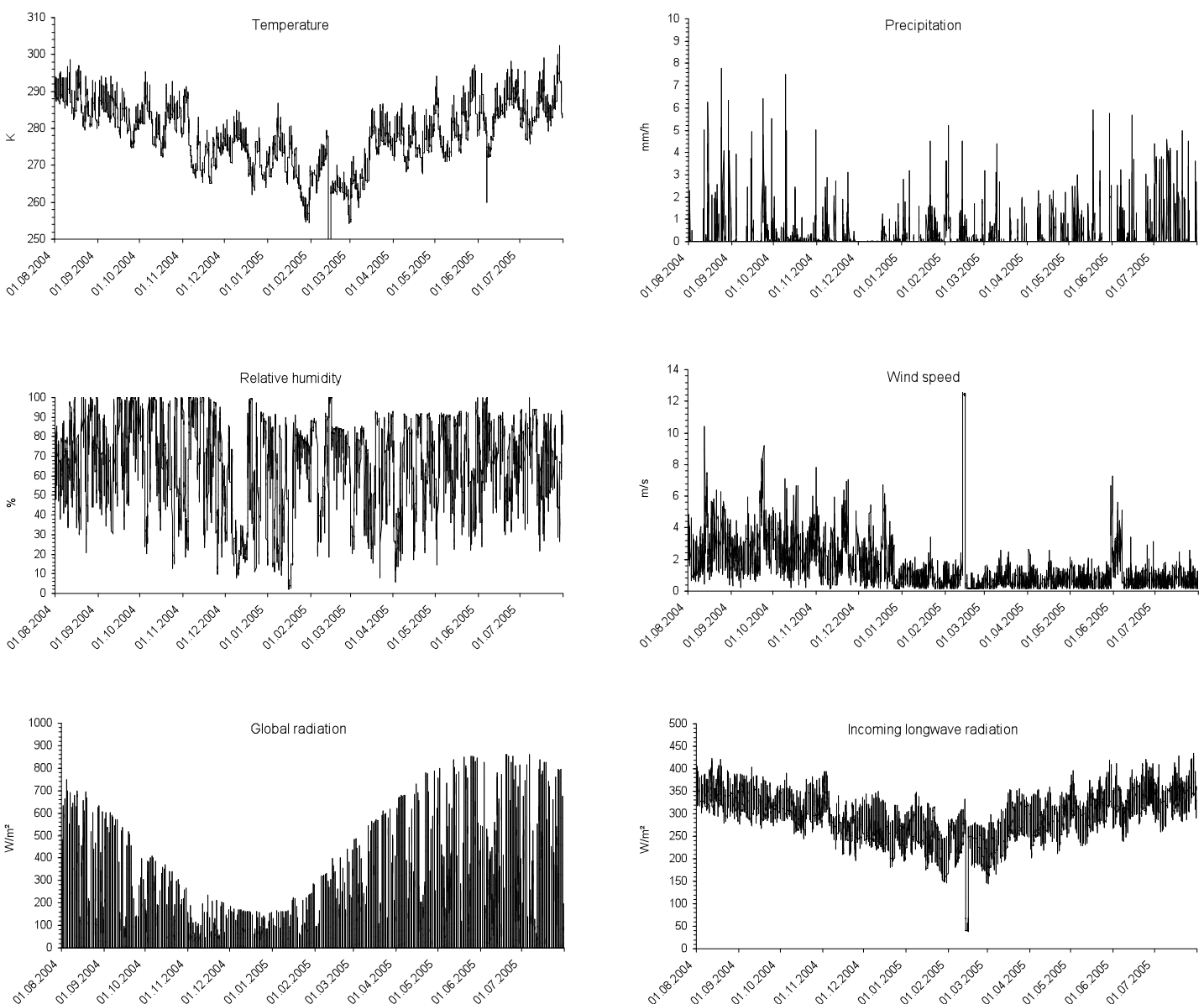

Fig. 3. Hourly meteorological observations from Kuehroint AWS (1407 ma.s.1.) used for the simulations with ESCIMO.spread. The diagrams show the uncorrected meteorological recordings.
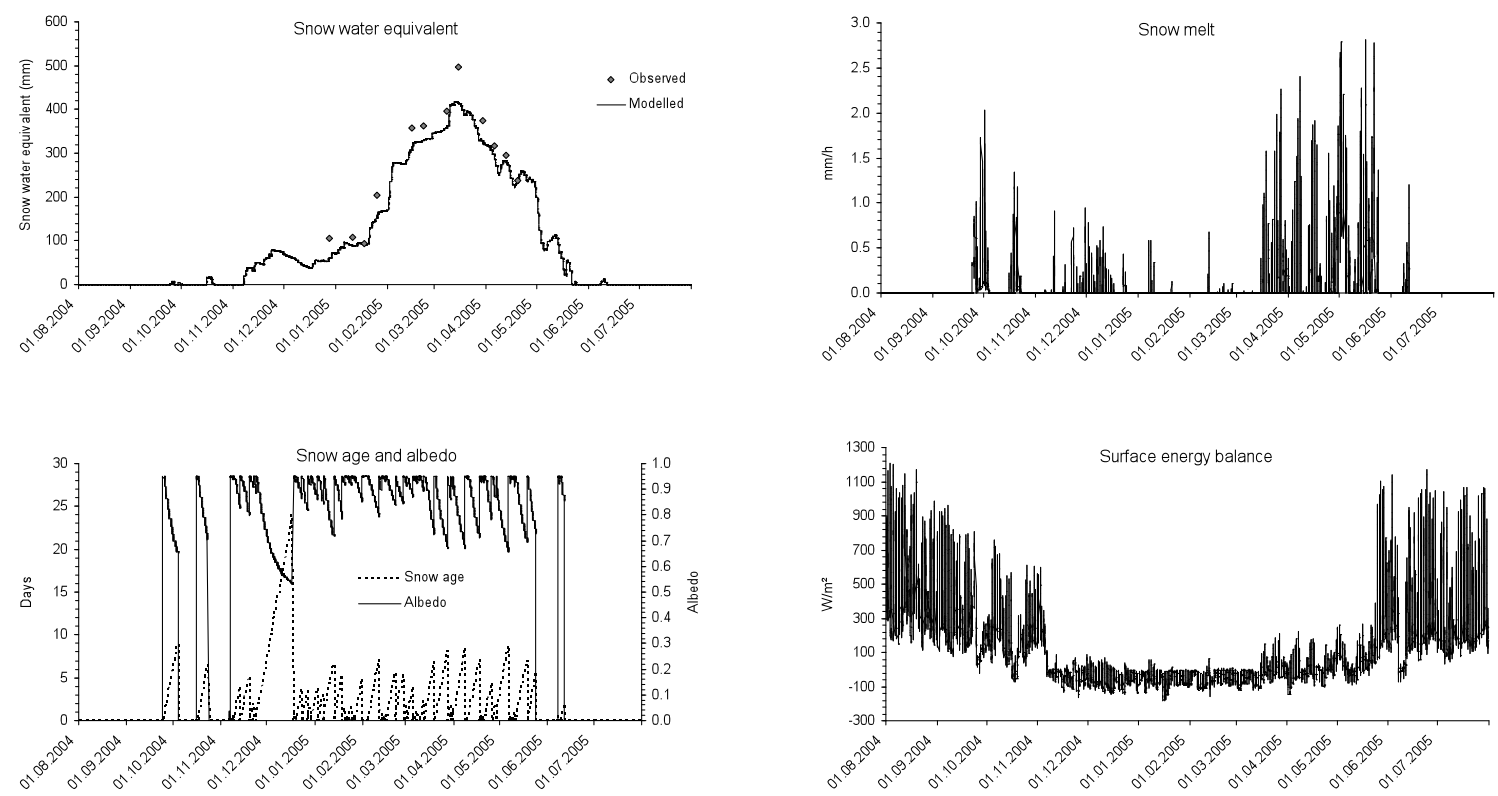

Fig. 4. Results of the ESCIMO.spread model run for the example data. 
For a more detailed description of the statistical features related to the implemented efficiency criteria the reader is refered to Krause et al. (2005).

In the case of the exemplary model run presented in this paper, all three criteria $\left(R^{2}=0.97, \mathrm{IA}=0.97\right.$ and NSME $=0.90$ ) show that ESCIMO is capable to simulate the observed snow water equivalent at our site with good accuracy. However, for the meteorological input data provided here, such quantitative validation is virtually tentative due to the errors consciously left for individual correction. Nonetheless, modelled SWE as compared with snow pit recordings shows a good agreement with the weekly pit recordings of SWE which have been conducted (Fig. 4), exhibiting that the model is quite robust when intermittent data errors occur.

ESCIMO has been validated in the framework of a variety of studies over a wide range of temporal and spatial scales. At the plot scale, the model has already been compared with measurements of several Alpine sites (Zappa et al., 2003; Strasser et al., 2002). Strasser et al. (2002) compared $E S C I M O$ to the sophisticated, multi-layer snow model CROCUS (Brun et al., 1992). ESCIMO has further been tested within the framework of the international SNOWMIP programmes (Etchevers et al., 2004; Rutter et al., 2010), including comparison with observations at middle elevation temperate, high elevation temperate, eastern US and arctic sites (Berms, Canada; Goose Bay, Canada; Fraser, US; Sleepers River, US; Hyytilälä, Finland; Hitsujigaoka, Japan). Distributed ESCIMO analyses have been conducted at the regional scale using satellite-data derived snow cover for different regions (Strasser and Mauser, 2001; Prasch et al., 2008a; Strasser, 2008). All comparisons exhibit that the snow cover scheme is capable of providing adequate estimates of the ground snow cover distribution for many types of application.

\section{Application in climate change conditions}

As described in Sect. 3 of this paper, ESCIMO.spread gives the option to define a set of climate change parameters in order to facilitate the analysis of climate change impacts on the snow cover at a specific site or to analyze the models sensitivity to changes in temperature and precipitation input. To give an example for an application under scenario conditions, ESCIMO.spread has been set up for two different scenario runs. The baseline scenario assumed here is a projected global average surface warming of $+2.8^{\circ} \mathrm{C}$ at the end of the 21 st century. This warming trend of $+0.28^{\circ} \mathrm{C}_{\text {year }}{ }^{-1}$ in the mean corresponds to the IPCC A1B scenario (IPCC, 2007). Analysis will be carried out for a 50 year projection horizon resulting in an increase of temperature of $+1.4{ }^{\circ} \mathrm{C}$ up to the winter $2054 / 2055$ (scenario 1). A second scenario will be assessed by combining the assumed temperature increase with a shift in

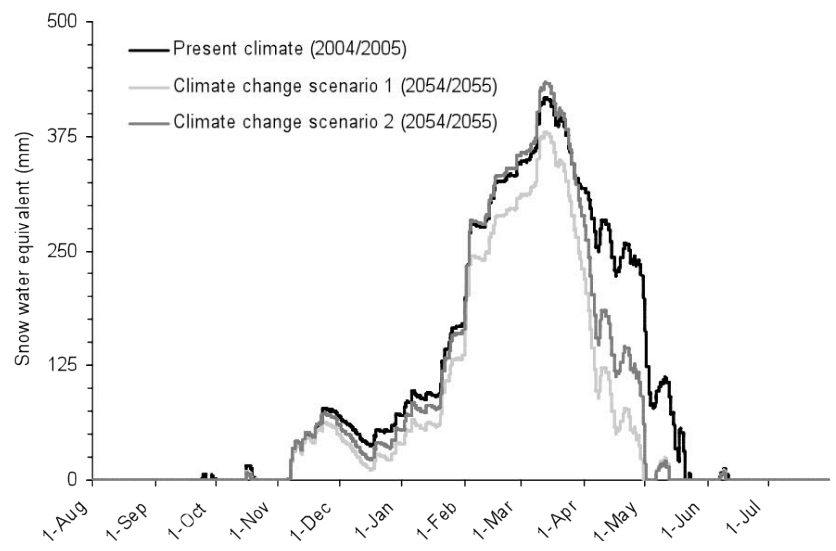

Fig. 5. Simulated snow water equivalent at the Kuehroint site under present and potential future climate conditions.

precipitation amount from the summer to the winter season, as predicted by several modelling studies that have been carried out for the region of Bavaria (MPI, 2010; KLIWA, 2007; BayFORKLIM, 1996). Thereby, a decrease of $10 \%$ in summer and an increase of $10 \%$ in winter is assumed up to the year 2055 (scenario 2). The results of both scenario runs are illustrated in comparison to the simulation results achieved for 2004/2005 in Fig. 5. As the figure exhibits, the increase in temperature alone as defined for scenario 1 remarkably reduces the duration of the snow covered season by enhanced melt intensity in spring. Although the shape of the curve is still very similar to the one achieved for present climate conditions, the simulated snow water equivalent is almost permanently less in this scenario run. As a result of the reduced storage of water in the snowpack, the annual total amount of snow melt is lowered from $838 \mathrm{~mm}(2004 / 2005)$ to $673 \mathrm{~mm}(2054 / 2055)$. In scenario 2 , this decrease in snow water equivalent and snow melt is partly compensated by the increase of winter precipitation ( $+10 \%)$, leading to an annual snow melt of $721 \mathrm{~mm}$. As observed in Fig. 5 for March, an increase in precipitation, even if combined with an increase in temperature as assumed for scenario 2, can temporarily increase snow water equivalent. The duration of the snow covered period is however not prolonged, as it is rather goverened by temperature than by precipitation. It mounts to 177 days for both scenario runs, compared to 197 days simulated for present climate conditions (2004/2005).

\section{Conclusions}

This paper describes the application of the spreadsheetbased, point snow surface energy and mass balance model ESCIMO.spread. The model formulae are packed together with one year of example data, the parameters and the graphical visualization of both the observations and the model results in a spreadsheet file which can be obtained 
from the authors free of charge. Hourly model calculations compare well to weekly recordings of snow water equivalent at an Alpine site in the Bavarian Alps. Beyond the application for past climate conditions, the model allows to simulate the effect of potential future climate change by means of parameters which modify observed temperature and/or precipitation. The model runs fast on any standard $\mathrm{PC}$ and platform with common spreadsheet programs, it is easy to handle and hence, it is suitable to be applied for educational purposes such as student courses.

The representation of the physical processes in ESCIMO.spread has proven to be robust and transferable in many applications already. The next future extension will be the adaption to simulating glacier surfaces (glacier ice, superimposed ice and debris-covered ice). The portability of the spreadsheet version of the model makes it particularly suitable to be taken to the field, and model the course of the seasonal evolution of a snow cover in situ by hooking up to a datalogger at any AWS, reading the data and performing the simulations directly. This exercise will next be undertaken by the authors at Freya glacier, NE-Greenland $\left(74^{\circ} 30^{\prime} \mathrm{N}\right.$, $\left.21^{\circ} 00^{\prime} \mathrm{W}\right)$.

Acknowledgements. Numerous colleagues have contributed to the development and application of the model described with their experience and practical support. Namely our colleagues Monika Prasch and Markus "Wasti” Weber (both Munich) provided their knowledge, expertise and technical skills to facilitate the development of ESCIMO. The latter also improved an earlier version of the manuscript of this paper at the scientific level and checked the mathematical expressions. Stefanie Mayer (Munich) and Michael Warscher (Garmisch-Partenkirchen) processed the station recordings. The Bavarian Avalanche Warning Service (Munich) provided support and service for constructing and maintaining the AWS at Kuehroint and the rangers of the National Park Administration performed the field observations to gather the validation data. Ruth Kalthaus improved the English of the final version of the manuscript. Most of all, Helmut Franz and Michael Vogel (all Berchtesgaden) continuously support our work with generous sponsorship and also provide the data which come with the model. Their encouragement is particularly appreciated here!

Edited by: C. Ritz

\section{References}

BayFORKLIM: Klimaatlas von Bayern, Bayerischer Klimaforschungsverbund (Bay-FORKLIM), 1996 (in German).

Brock, B. W. and Arnold, N. S.: A spreadsheet-based (Microsoft Excel) point surface energy balance model for glacier and snow melt studies, Earth Surf. Proc. Land., 25, 649-658, 2000.

Brun, E., David, P., Sudul, M., and Brunot, G.: A numerical model to simulate snow-cover stratigraphy for operational avalanche forecasting, J. Glaciol., 38(128), 13-22, 1992.
Etchevers, P., Martin, E., Brown, R., Fierz, C., Lejeune, Y., Bazile, E., Boone, A., Dai, Y.-J., Essery, R. L. H., Fernandez, A., Gusev, Y., Jordan, R., Koren, V., Kowalczyk, E., Nasonova, N. O., Pyles, R. D., Schlosser, A., Shmakin, A. B., Smirnova, T. G., Strasser, U., Verseghy, D., Yamazaki, T., and Yang, Z.-L.: Validation of the surface energy budget simulated by several snow models (SnowMIP project), Ann. Glaciol., 38, 150-158, 2004.

IPCC: Climate Change 2007: The Physical Science Basis, in: Contribution of Working Group I to the Fourth Assessment Report of the Intergovernmental Panel on Climate Change edited by: Solomon, S., Qin, D., Manning, M., Chen, Z., Marquis, M., Averyt, K. B., Tignor, M., and Miller, H. L., Cambridge University Press, Cambridge, United Kingdom and New York, 2007.

KLIWA: Klimaveränderung und Konsequenzen für die Wasserwirtschaft, in: Fachvorträge des KLIWA-Symposiums am 25-26 September (Stuttgart), Kliwa-Berichte, Karlsruhe, 10, 256 pp., 2007 (in German).

Krause, P., Boyle, D. P., and Bse, F.: Comparison of different efficiency criteria for hydrological model assessment, Adv. Geosci., 5, 89-97, doi:10.5194/adgeo-5-89-2005, 2005.

Kuchment, L. S. and Gelfan, A. N.: The determination of the snowmelt rate and the meltwater outflow from a snowpack for modeling river runoff generation, J. Hydrol, 179, 23-36, 1996.

Ludwig, R., Mauser, W., Niemeyer, S., Colgan, A., Stolz, R., Escher-Vetter, H., Kuhn, M., Reichstein, M., Tenhunen, J., Kraus, A., Ludwig, M., Barth, M., and Hennicker, R.: Webbased modelling of energy, water and matter fluxes to support decision making in mesoscale catchments - The integrative perspective of GLOWA-Danube, Phys. Chem. Earth, 28, 621634, 2003.

Mauser, W. and Schädlich, S.: Modelling the spatial distribution of evapotranspiration on different scales using remote sensing data, J. Hydrol., 213, 250-267, 1998.

Mauser, W. and Ludwig, R.: GLOWA-DANUBE - A research concept to develop integrative techniques, scenarios and strategies regarding global changes of the water cycle, 2002, in: Climatic Change: Implications for the Hydrological Cycle and for Water Management, edited by: Beniston, M., Kluwer Academic Publishers, Dordrecht and Boston, Adv. Glob. Change Res., 10, 171-188, 2002.

Mauser, W., Prasch, M., and Strasser, U.: Physically based Modelling of Climate Change Impact on Snow Cover Dynamics in Alpine Regions using a Stochastic Weather Generator, Proceedings of the International Congress on Modelling and Simulation MODSIM07, Christchurch, New Zealand, 2007.

Mauser, W. and Bach, H.: PROMET - Large scale distributed hydrological modelling to study the impact of climate change on the water flows of mountain watersheds, J. Hydrol., 376, 362377, 2009.

MPI, Webpage of the Max Planck Institute for Meteorology (Hamburg, Germany), available at: www.mpimet.mpg.de/ wissenschaft/atmosphaere-im-erdsystem/arbeitsgruppen/ regionale-klimamodellierung-alt/remo-uba/, accessed August 2010.

Nash, J. E. and Sutcliffe, J. V.: River flow forecasting through conceptual models, a discussion of principles, J. Hydrol., 227, 33-51, 1970. 
Prasch, M., Strasser, U., and Mauser, W.: Validation of a physically based snow model for the simulation of the accumulation and ablation of snow (ESCIMO), in: Proceedings of the Alpine*Snow*Workshop (www.alpinesnowworkshop.org), Munich, Germany, 5-6 October 2006, edited by: Strasser, U. and Vogel, M., Nationalpark Berchtesgaden, Forschungsbericht Nr. 53, 2008a.

Prasch, M., Strasser, U., Bernhardt, M., Weber, M., and Mauser, W.: Physically based modelling of snow cover dynamics in Alpine regions, Proceedings of the International Congress "Managing Alpine Future - strategies for sustainability in times of change", Innsbruck, Austria, ISBN 978-3-7001-6571-2, 2008b.

Rutter, N., Essery, R. L. E., Pomeroy, J., Altimir, N., Andreadis, K., Baker, I., Barr, A., Bartlett, P., Elder, K., Ellis, C., Feng, X., Gelfan, A., Goodbody, G., Gusev, Y., Gustafsson, D., Hellström, R., Hirota, T., Jonas, T., Koren, V., Li, W.-P., Luce, C., Martin, E., Nasonova, O., Pumpanen, J., Pyles, D., Samuelsson, P., Sandells, M., Schädler, G., Shmakin, A., Smirnova, T., Stähli, M., Stöckli, R., Strasser, U., Su, H., Suzuki, K., Takata, K., Tanaka, K., Thompson, E., Vesala, T., Viterbo, P., Wiltshire, A., Xue, Y., and Yamazaki, T.: Evaluation of forest snow processes models (SnowMIP2), J. Geophys. Res., 114, D06111, doi:10.1029/2008JD011063, 2009.

Strasser, U.: Regionalisierung des Wasserkreislaufs mit einem SVAT-Modell am Beispiel des Weser-Einzugsgebiets, Münchener Geographische Abhandlungen, Munich, Reihe B, Band 28, 146 pp., ISBN 392530888 1, 1998 (in German).

Strasser, U. and Mauser, W.: Modelling the Spatial and Temporal Variations of the Water Balance for the Weser Catchment 19651994, J. Hydrol., 254(1-4), 199-214, 2001.

Strasser, U., Etchevers, P., and Lejeune, Y.: Intercomparison of two Snow Models with Different Complexity Using Data from an Alpine Site, Nord. Hydrol., 33(1), 15-26, 2002.
Strasser, U., Bernhardt, M., Weber, M., Liston, G. E., and Mauser, W.: Is snow sublimation important in the alpine water balance?, The Cryosphere, 2, 53-66, doi:10.5194/tc-2-53-2008, 2008.

Strasser, U.: Die Modellierung der Gebirgsschneedecke im Nationalpark Berchtesgaden (Modelling of the mountain snow cover in the Berchtesgaden National Park, Berchtesgaden National Park research report), Berchtesgaden, Nr. 55, 2008 (in German).

Strasser, U. and Mauser, W.: Using a stochastic climate generator for simulating global warming effects on the water resources in a mountain basin, Geophysical Research Abstracts, Abstracts of the European Geosciences Union General Assembly 2006, Vienna, Austria, 2006.

Strasser, U., Corripio, J., Brock, B., Pellicciotti, F., Burlando, P., and Funk, M.: Spatial and Temporal Variability of Meteorological Variables at Haut Glacier d'Arolla (Switzerland) During the Ablation Season 2001: Measurements and Simulations, J. Geophys. Res., 109, D03103, doi:10.1029/2003JD003973, 2004.

Taschner, S., Strasser, U., and Mauser, W.: Modelling the Spatial Snow Water Equivalent Using NOAA-AVHRR Data for Mesoscale Catchments, SPIE Proc. Series, Proceedings of the EUROPTO 1998 Conference, Barcelona, 1998.

Willmot, C. J.: On the evaluation of model performance in physical geography, in: Spatial Statistics and Models, edited by: Gaile, G. L. and Willmot, C. J., D. Reidel, Dordrecht, 443-460, 1984.

Zappa, M., Pos, F., Strasser, U., Warmerdam, P., and Gurtz, J.: Seasonal water balance of an Alpine catchment as evaluated by different methods for spatially distributed snow melt modelling, Nord. Hydrol., 34(3), 179-202, 2003. 